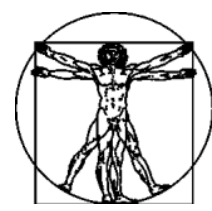

\title{
УСКОРЕНИЕ ГОЛОВЫ СПОРТСМЕНА ПРИ ВЫПОЛНЕНИИ СИЛОВЫХ ПРИЕМОВ В ХОККЕЕ С ШАЙБОЙ
}

\author{
А.В. Самсонова, Л.В. Михно, Л.Л. Ципин, Г.А. Самсонов, И.А. Чичелов
}

Национальный государственный университет физической культуры, спорта и здоровья имени П.Ф. Лесгафрта, Россия, 190121, Санкт-Петербург, ул. Декабристов, 35, e-mail: spb_biomechanics@rambler.ru

\begin{abstract}
Аннотация. В современном хоккее с шайбой силовые приемы являются одним из основных элементов противодействия противнику. Однако, наряду с другими игровыми действиями, они часто приводят к травмам. Одна из причин травм чрезмерное ускорение головы спортсмена, что особенно важно учитывать в детскоюношеском хоккее. В связи с этим в настоящей работе проведен анализ значений ускорения головы спортсмена при выполнении широко применяемых хоккеистами силовых приемов: «толчок плечом в плечо при параллельном движении» и «толчок плечом в плечо при встречном движении». Кроме того, рассмотрены запрещенные правилами, однако также применяемые в ряде случаев приемы: «толчок клюшкой в спину» и «толчок клюшкой в грудь». Ускорение головы определялось посредством специального акселерометрического устройства, включающего укрепленный на шлеме хоккеиста трехкоординатный датчик. В результате измерения ускорения головы двух хоккеистов-юношей среднего возраста при выполнении силовых приемов в процессе тренировки вне льда и на льду обнаружено, что наибольшего значения $(27,8 \pm 11,1) g$ ускорение головы достигает при выполнении вне льда запрещенного приема «толчок клюшкой в грудь». При этом максимальное ускорение $(50,4 g)$ зафиксировано при падении игрока на спину. Защитные действия игрока в остальных случаях привели к существенно меньшим значениям ускорения. На льду наибольших значений $(26,8 \pm 7,6) g$ ускорение головы достигает при выполнении приема «толчок плечом в плечо при параллельном движении». При этом максимальное ускорение $(42,3 g)$ зафиксировано в случае, когда толчок пришелся преимущественно в плечо, а не в спину. Таким образом, формирование технически правильных защитных действий игрока как при тренировке вне льда, так и на льду позволяет снизить риск возникновения травм головы.
\end{abstract}

Ключевые слова: хоккей с шайбой, детско-юношеский спорт, силовые приемы, ускорение головы, травмы.

\section{ВВЕДЕНИЕ}

Хоккей с шайбой представляет собой один из наиболее травмоопасных видов спорта. По статистике, хоккей с шайбой занимает четвертое место по частоте травмирования после бокса, регби и сноуборда [2]. Показано, что причиной 23,9 \% всех травм в хоккее является контакт с игроком [6]. Американские ученые свидетельствуют,

(C) Самсонова А.В., Михно Л.В., Ципин Л.Л., Самсонов Г.А., Чичелов И.А., 2015

Самсонова Алла Владимировна, д.пед.н., профессор, заведующая кафедрой биомеханики, Санкт-

Петербург

Михно Леонид Владимирович, д.пед.н., профессор, заведующий кафедрой теории и методики хоккея,

Санкт-Петербург

Ципин Леонид Львович, к.пед.н., профессор кафедры биомеханики, Санкт-Петербург

Самсонов Глеб Александрович, аспирант кафедры биомеханики, Санкт-Петербург

Чичелов Иван Александрович, аспирант кафедры теории и методики хоккея, Санкт-Петербург 
что из-за столкновений (включая контакты с бортом, с игроками, со льдом) происходят $44 \%$ травм, и они занимают первое место среди всех причин травматизма [3].

Согласно проведенным исследованиям, удар стандартной хоккейной шайбы массой 160 г, летящей со скоростью 33 м/с, о хоккейный шлем вызывает ускорение головы спортсмена, равное $(110,2 \pm 7,4) g$ [5]. Чтобы уменьшить количество возможных травм, хоккеисты используют специальную экипировку. Достаточно больших значений ускорение головы спортсмена может также достигать при выполнении различных силовых приемов, т.е. приемов игры туловищем, ногами и плечами, сопровождающихся остановками, толчками и прижиманием игрока противника. Однако в настоящее время как в нашей стране, так и за рубежом отсутствуют исследования, посвященные изучению ускорения головы спортсмена при выполнении силовых приемов в хоккее. Особенно актуальны эти исследования в детско-юношеском хоккее, так как, несмотря на запрет использования силовых приемов игроками до 11 лет, они в ряде случаев применяются юношами этого возраста и еще более широко юношами среднего и старшего возрастов. По данным недавно проведенного общенационального американского исследования, сотрясения мозга, связанные в том числе с проведением силовых приемов, более распространены среди лиц в возрасте до 18 лет (9\% всех травм), чем среди более старших спортсменов (3,7 \% всех травм). Одна из причин этого заключается в том, что мозг детей и подростков более подвержен черепно-мозговой травме, чем мозг взрослого человека, даже при меньшей силе удара [4].

Силовые приемы применяются хоккеистами в соревнованиях и на тренировках на льду, а также отрабатываются вне льда, что особенно характерно для юных спортсменов [1]. В процессе игры также имеют место запрещенные правилами приемы, за которые игрок получает штраф. В связи с этим в настоящем исследовании были поставлены следующие задачи:

1. Оценить значение ускорения головы спортсмена при выполнении часто применяемых силовых приемов.

2. Сравнить значение результирующего ускорения головы спортсмена при выполнении силовых приемов вне льда (в зале) и на льду.

3. Сравнить значение результирующего ускорения головы спортсмена при выполнении разрешенных и запрещенных силовых приемов.

\section{МАТЕРИАЛЫ И МЕТОДЫ ИССЛЕДОВАНИЯ}

В исследовании принимали участие два хоккеиста-юноши, характеристика которых представлена в табл. 1.

Для определения ускорения головы спортсмена использовалось специальное акселерометрическое устройство, позволяющее дистанционно производить измерения в режиме реального времени, отображать и сохранять результаты на компьютере (ООО «Телеком-Диагностика», г. Санкт-Петербург). Данное устройство включает акселерометрический датчик на основе трехкоординатного $M E M S$-акселерометра (рис. 1), радиопередающий модуль стандарта Bluetooth и ресивер.

Таблииа 1

Данные спортсменов, участвующих в экспериментах

\begin{tabular}{|c|c|c|c|c|c|}
\hline Спортсмен & Год рождения & Амплуа & Рост, см & Вес, кг & $\begin{array}{c}\text { Стаж } \\
\text { занятий, лет }\end{array}$ \\
\hline 1 & 2002 & Нападающий & 158 & 47 & 8 \\
\hline 2 & 2001 & Защитник & 172 & 57 & 7 \\
\hline
\end{tabular}




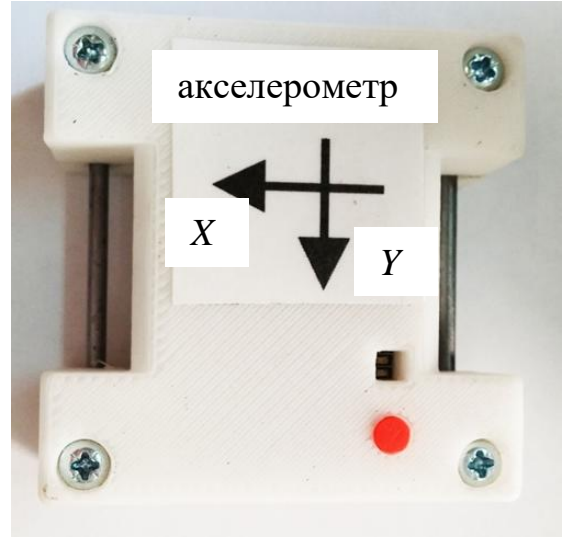

$a$

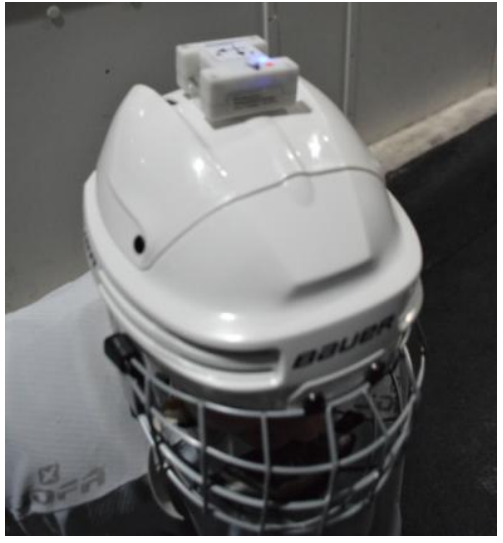

6

Рис. 1. Акселерометрический датчик ( $a$ ) и его крепление на шлеме хоккеиста (б)

Акселерометрический датчик работает в двух диапазонах: $(0 \ldots 2) g$ и $(0 \ldots 16) g$. Частота оцифровки составляет до 1000 Гц, размер датчика $-55 \times 55 \times 25$ мм, масса -50 г. Датчик прикрепляется к шлему игрока, против которого применяется силовой прием. Направление оси $X$ соответствует движениям головы спортсмена во фронтальной плоскости, оси $Y$ - в сагиттальной плоскости, оси $Z$ - в трансверсальной плоскости (см. рис. 1). Результирующее ускорение головы спортсмена определялось по формуле

$$
a=\sqrt{a_{X}^{2}+a_{Y}^{2}+a_{Z}^{2}} .
$$

Совместно с записью акселерограмм производилась видеосъемка движений спортсменов с частотой 30 кадров в секунду. Статистическая обработка результатов осуществлялась в пакете Statgraphics Centurion.

При изучении силовых приемов вне льда исследуемые были в полной хоккейной экипировке с клюшками, но без коньков. Для предупреждения травм использовались гимнастические маты. Изучение силовых приемов на льду проходило в обычных условиях.

Как вне льда, так и на льду выполнялись четыре часто применяемые в хоккее силовых приема:

1. Толчок плечом в плечо при параллельном движении.

2. Толчок клюшкой в спину.

3. Толчок клюшкой в грудь.

4. Толчок плечом в плечо при встречном движении.

Первый и четвертый приемы выполнялись в рамках правил, допустимых Международной федерацией хоккея на льду (International Ice Hockey Federation, IIHF). При этом контакт происходил без использования локтя, кулака, клюшки или колена. Второй и третий приемы являются запрещенными правилами и наказываются дисциплинарными штрафами во время матча. При их выполнении существует большая вероятность во время падения удариться головой о лед или борт, что может привести к травмам головы.

\section{РЕЗУЛЬТАТЫ И ИХ ОБСУЖДЕНИЕ}

На рис. 2 показано ускорение головы спортсмена при выполнении силовых приемов вне льда. Представлена одна из трех попыток выполнения каждого приема, в которой значение результирующего ускорения головы максимально. В табл. 2 приведены максимальные и средние значения ускорений для всех попыток. 

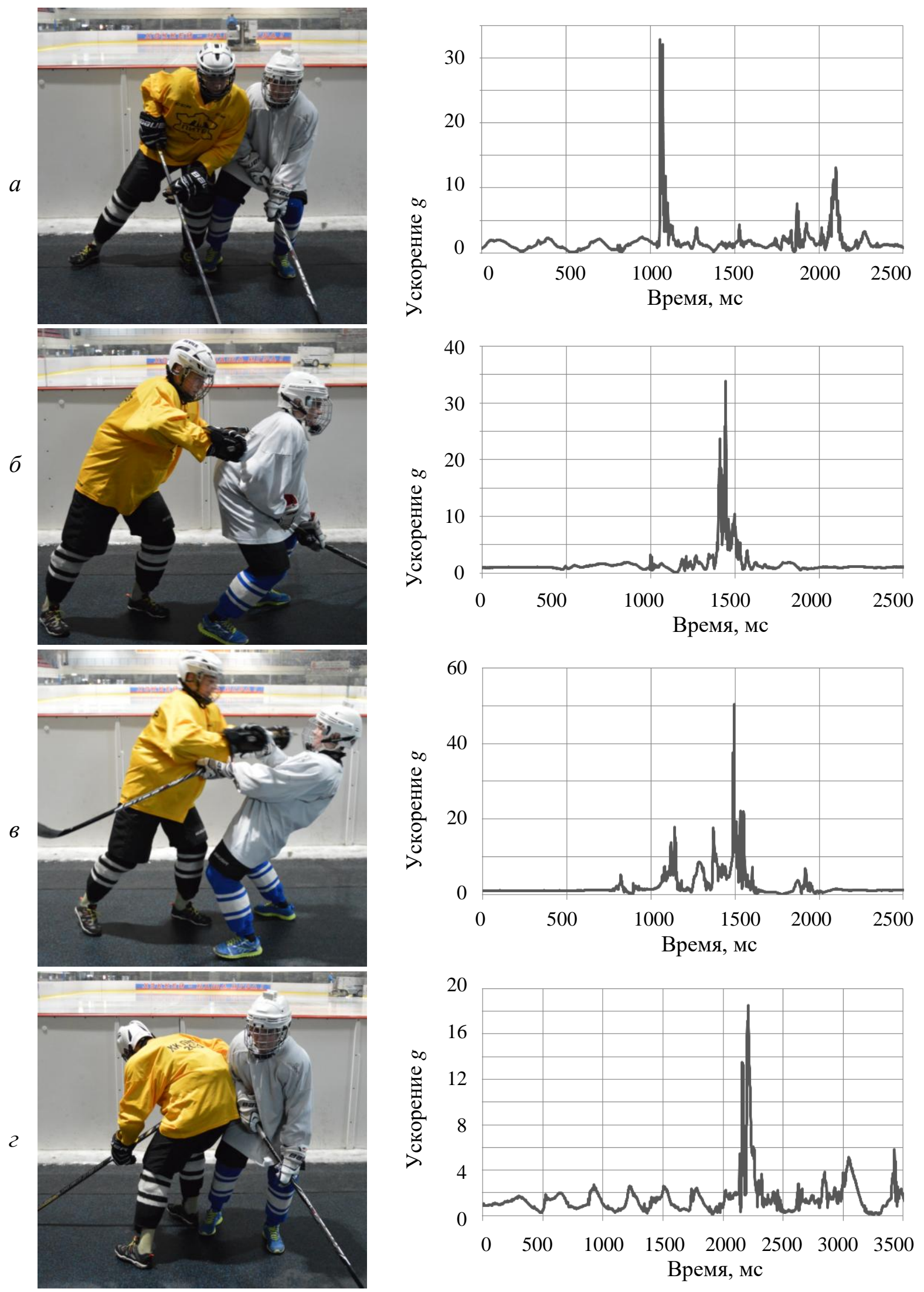

Рис. 2. Выполнение силовых приемов (слева) и ускорение головы спортсмена (справа) при исследовании вне льда. Приемы: $a$ - толчок плечом в плечо при параллельном движении; $\sigma$ - толчок клюшкой в спину; 6 - толчок клюшкой в грудь; 2 - толчок плечом в плечо при встречном движении 
Таблииа 2

Ускорение головы спортсмена при выполнении силовых приемов вне льда $g$

\begin{tabular}{|c|c|c|c|c|c|}
\hline \multirow{2}{*}{$\begin{array}{c}\text { Номер } \\
\text { приема }\end{array}$} & Название приема & \multicolumn{3}{|c|}{ Номер попытки } & \multirow{2}{*}{ M } \\
\cline { 3 - 5 } & 1 & 1 & 2 & 3 & \\
\hline 2 & $\begin{array}{c}\text { Толчок плечом в плечо } \\
\text { при параллельном движении }\end{array}$ & $\mathbf{3 2 , 9}$ & 7,0 & 10,8 & $16,9 \pm 7,9$ \\
\hline 3 & Толчок клюшкой в спину & $\mathbf{3 3 , 8}$ & 8,2 & 7,1 & $16,4 \pm 8,5$ \\
\hline 4 & Толчок клюшкой в грудь & $\mathbf{5 0 , 4}$ & 18,2 & 14,9 & $27,8 \pm 11,1$ \\
\hline & $\begin{array}{c}\text { Толчок плечом в плечо } \\
\text { при встречном движении }\end{array}$ & 14,4 & 9,7 & $\mathbf{1 8 , 6}$ & $14,2 \pm 2,4$ \\
\hline
\end{tabular}

Примечание. Здесь и в табл. 3 жирным выделены максимальные значения.

На рис. 2 видно что, при выполнении вне льда силового приема «толчок плечом в плечо при параллельном движении» максимальное ускорение головы составляет $32,9 g$. Это ускорение соответствует моменту толчка. Второй пик $(13,1 g)$ приходится на момент касания мата рукой и затем плечом и головой при падении. Значения ускорения во второй и третьей попытках значительно ниже (см. табл. 2). Это связано с меньшей силой толчка и с тем, что спортсмен после толчка более упруго приземляется на маты на обе руки и ноги.

Максимальное ускорение головы при выполнении силового приема «толчок клюшкой в спину» достигает $33,8 g$. Оно соответствует удару головы о мат после падения на колени и руки. Во второй попытке также происходит падение на колени и руки, а в третьей - на бок, но в обоих случаях без удара головы о мат, что приводит к меньшим значениям ускорения.

Силовой прием «толчок клюшкой в грудь» сопровождается самым большим максимальным ускорением головы $50,4 g$. Такое высокое значение ускорения вызвано тем, что в первой попытке спортсмен после толчка клюшкой падает плашмя на спину. В двух других попытках падение назад в сторону с перекатом на спину происходит менее жестко.

Максимальное ускорение головы при выполнении силового приема «толчок плечом в плечо при встречном движении» составляет в момент толчка 18,6 $g$ и существенно ниже в сравнении с другими приемами. Все три попытки по технике выполнения примерно одинаковы и различаются в основном силой толчка, которая в третьей попытке самая большая.

Сравнение между собой всех рассмотренных силовых приемов показывает, что наибольшее среднее значение ускорения головы при их выполнении вне льда $(27,8 \pm 11,1) g$ наблюдается при выполнении приема «толчок клюшкой в грудь» (см. табл. 2). Оно примерно в 1,7 раза превышает аналогичные значения при выполнении других приемов. Характерно, что данный прием является запрещенным, и полученные высокие значения ускорения головы даже при выполнении приема вне льда подтверждают его травмоопасность. Средние значения ускорения головы при выполнении остальных приемов мало отличаются.

На рис. 3 показаны ускорения головы спортсмена при выполнении силовых приемов на льду. Как и в предыдущем случае, представлена одна из трех попыток выполнения каждого приема, в которой значение результирующего ускорения головы максимально. В табл. 3 приведены максимальные и средние значения ускорений для всех попыток. 

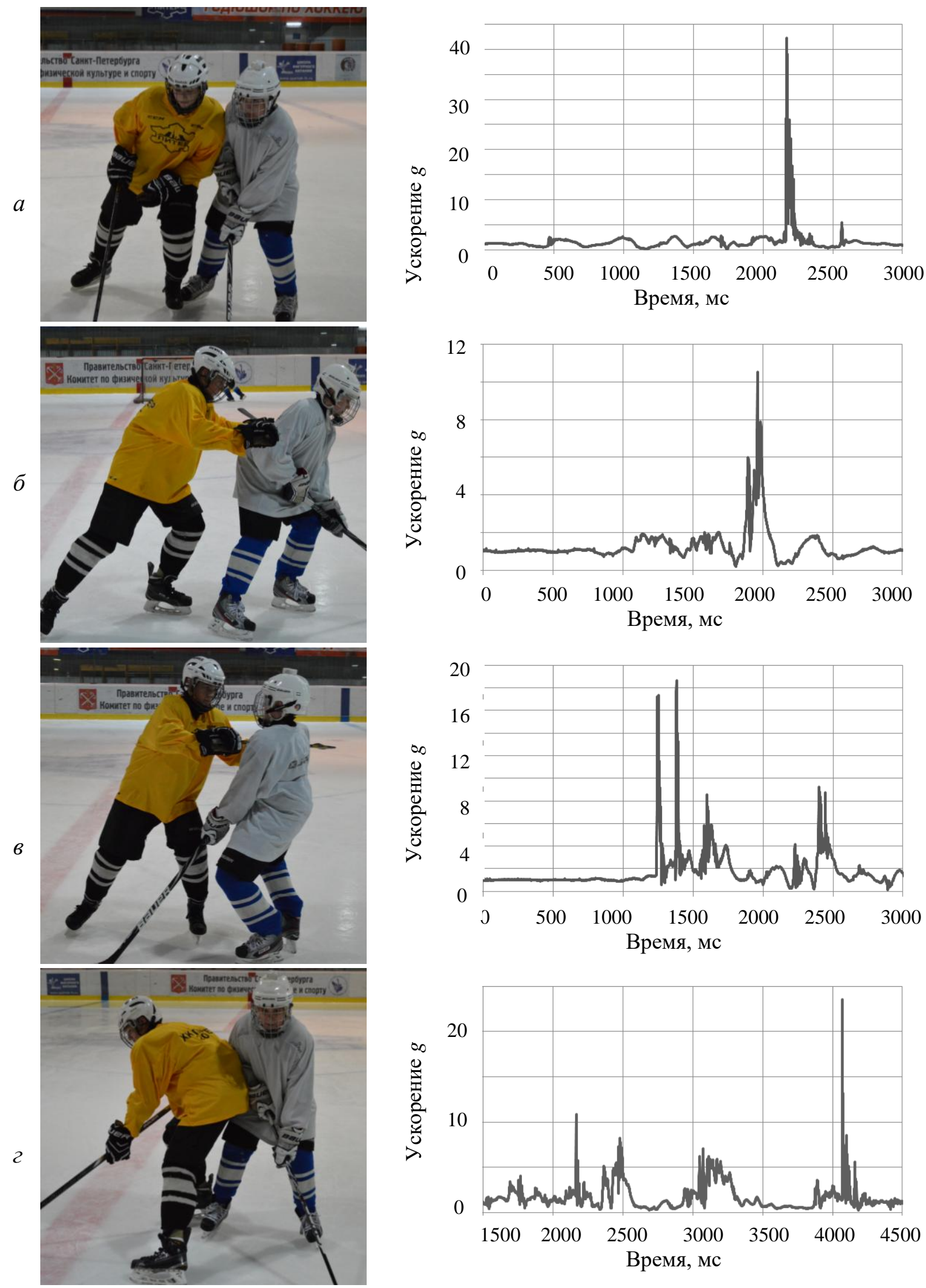

Рис. 3. Выполнение силовых приемов (слева) и ускорение головы спортсмена (справа) при исследовании на льду. Приемы: $a$ - толчок плечом в плечо при параллельном движении; $\sigma$ - толчок клюшкой в спину; 8 - толчок клюшкой в грудь; 2 - толчок плечом в плечо при встречном движении 
Ускорение головы спортсмена при выполнении силовых приемов на льду $g$

\begin{tabular}{|c|c|c|c|c|c|}
\hline \multirow{2}{*}{$\begin{array}{c}\text { Номер } \\
\text { приема }\end{array}$} & Название приема & \multicolumn{3}{|c|}{ Номер попытки } & \multirow{2}{*}{ M } \\
\cline { 3 - 5 } & 1 & 1 & 2 & 3 & \\
\hline 2 & $\begin{array}{c}\text { Толчок плечом в плечо } \\
\text { при параллельном движении }\end{array}$ & 19,7 & 18,5 & $\mathbf{4 2 , 3}$ & $26,8 \pm 7,6$ \\
\hline 3 & Толчок клюшкой в спину & $\mathbf{1 0 , 5}$ & 2,7 & 2,4 & $5,2 \pm 2,6$ \\
\hline 4 & Толчок клюшкой в грудь & $\mathbf{1 8 , 6}$ & 9,8 & 15,0 & $14,5 \pm 2,4$ \\
\hline
\end{tabular}

Как видно на рис. 3, при выполнении на льду силового приема «толчок плечом в плечо при параллельном движении» максимальное ускорение головы составляет 42,3g и приходится на момент толчка. Характерно, что толчок производится преимущественно в плечо, а не в спину. Значения ускорения в других попытках (см. табл. 3) ниже в связи с тем, что игрок, против которого выполняется прием, встречает атакующего игрока менее жестко с отведением туловища в сторону.

Силовой прием «толчок клюшкой в спину» сопровождается падением спортсмена на лед на колени и руки, что приводит к максимальному ускорению головы $10,5 g$. В двух других попытках падения не происходит и значения ускорения в несколько раз меньше.

При выполнении силового приема «толчок клюшкой в грудь» первый пик ускорения 17,3g возникает в момент толчка в грудь, а максимальное ускорение головы $18,6 g$ - непосредственно за ним при ударе клюшкой в маску шлема. Падение после толчка на колени и руки вызывает ускорение $9,3 g$. В остальных попытках при меньшей силе толчка большее ускорение наблюдается не при самом толчке, а при падении.

Силовой прием «толчок плечом в плечо при встречном движении» отличается тем, что при толчке развивается ускорение $10,9 g$, а при падении с ударом головой о лед - максимальное ускорение $23,5 g$. Во второй и третьей попытках при падении удара головой о лед не было и значения ускорения, соответственно, были ниже.

В отличие от выполнения силовых приемов вне льда, на льду наибольшее среднее значение ускорения головы $(26,8 \pm 7,6) g$ наблюдается для приема «толчок плечом в плечо при параллельном движении» (см. табл. 3). Это объясняется тем, что скорость движения хоккеистов на льду и сила соударения существенно выше, чем вне льда. Прием «толчок клюшкой в грудь», при выполнении которого вне льда отмечается высокое среднее значение ускорения головы, на льду приводит к меньшему ускорению $(14,5 \pm 2,4) g$. Можно предположить, что, тренируясь вне льда и зная, что падение будет происходить на мягкую поверхность, спортсмены меньше заботятся о предотвращении падений, и выполнение этого приема менее травмоопасно. Это же касается приема «толчок клюшкой в грудь». Средние значения ускорения головы при выполнении приема «толчок плечом в плечо при встречном движении» вне льда и на льду сопоставимы.

Анализируя максимальные зафиксированные значения ускорения головы $50,4 \mathrm{~g}$ и $42,3 g$, следует отметить, что они близки к тем, которые могут привести к потере устойчивости или даже к нокауту в боксе, т.е. достаточно травмоопасны [7]. Вместе с тем необходимо учитывать, что хоккейный шлем, на котором укреплен 
акселерометрический датчик, имеет демпфирующие прокладки, и в связи с этим измеряемое ускорение, в частности при ударе головой о лед или о мат при падении, может несколько отличаться от действительного ускорения головы спортсмена.

\title{
ЗАКЛЮЧЕНИЕ
}

Измерение ускорения головы спортсмена с помощью специального акселерометрического устройства показало, что при выполнении используемых в хоккее с шайбой силовых приемов развиваются достаточно большие ускорения, которые могут служить причиной травм, в частности сотрясений головного мозга. Высокие значения ускорения отмечаются при изучении и отработке силовых приемов как вне льда, так и на льду. Вне льда наибольшее среднее значение ускорения головы отмечается при выполнении запрещенного правилами приема «толчок клюшкой в грудь», а на льду - разрешенного приема «толчок плечом в плечо при параллельном движении». Вне льда большое ускорение связано в основном с падением игрока, а на льду - с соударением игроков. Правильная техника движений игрока при выполнении против него силовых приемов позволяет существенно снизить ускорения и тем самым предотвратить травмы головы, что особенно важно для юных хоккеистов.

\section{СПИСОК ЛИТЕРАТУРЫ}

1. Железняк Ю.Д., Портнов Ю.М., Савин В.П., Лексаков А.В. Спортивные игры: техника, тактика, методика обучения: учеб. для студ. высш. пед. учеб. заведений / под ред. Ю.Д. Железняка, Ю.М. Портнова. - 2-е изд., стереотип. - М.: Академия, 2004. - 520 с.

2. Agel J., Dompier T.P., Dick R., Marshall S.W. Descriptive epidemiology of collegiate men's ice hockey injuries: National Collegiate Athletic Association Injury Surveillance System, 1988-1989 through 2003-2004 // Journal of Athletic Training. - 2007. - Vol. 42, № 2. - P. 241-248.

3. Caputo P., Mattson D.J. Recreational ice hockey injuries in adult non-checking leagues: a United States perspective // Journal of Science and Medicine in Sport. - 2005. - Vol. 4. - P. 58-65.

4. Deits J., Yard E.E., Collins C.L., Fields S.K., Comstock R.D. Patients with ice hockey injuries presenting to US emergency departments, 1990-2006 // Journal of Athletic Training. - 2010. - Vol. 45, № 5. - P. 467-474.

5. Ouckama R., Pearsall D.J. Projectile impact testing of ice hockey helmets: headform kinematics and dynamic measurement of localized pressure distribution // IRCOBI Conference, 2014. - P. 62-71.

6. Pettersson M., Lorentzon R. Ice hockey injuries: a 4-year prospective study of a Swedish élite ice hockey team // British Journal of Sports Medicine. - 1993.- Vol. 27, № 4. - P. 251-254.

7. Walilko T.J., Viano D.C., Bir C.A. Biomechanics of the head for Olympic boxer punches to the face // British Journal of Sports Medicine. - 2005. - Vol. 39. - P. 710-719.

\section{ATHLETE'S HEAD ACCELERATION WHILE PERFORMING CHECKING IN THE ICE HOCKEY}

\author{
A.V. Samsonova, L.V. Mikhno, L.L. Tsipin, G.A. Samsonov, I.A. Chichelov \\ (Saint Petersburg, Russia)
}

Checking is one of the main ways of countering an opponent in the modern ice hockey. Howewer, just like other game actions, they frequently lead to injuries. Excessive head acceleration is one of the traumatic causes and it is especially important to account in the minor and junior hockey. Therefore, this article concerns the analysis of the head acceleration values while performing widely used checking moves - the shoulder checking in parallel move and the body checking in counter move. Moreover, an illegal checking (a crosschecking from the front and from the back), which is used in some situations, was also studied. Head acceleration was measured with the unique acceleration measurement system 
including the 3-axis accelerometer attached to the helmet. Measuring the head acceleration of two junior hockey players during the on-ice and off-ice training has shown that the head acceleration reaches its maximum value $(27.8 \pm 11.1) \mathrm{g}$ while performing the front crosschecking off-ice. Howewer, the maximum acceleration value $(50.4 \mathrm{~g})$ was recorded in an attempt where a player had fallen on a back. Player's defencive actions in the rest of the attempts resulted in a significantly smaller acceleration values. On-ice head acceleration reaches maximum values $(26.8 \pm 7.6) \mathrm{g}$ while performing the body checking in parallel move, and the maximum acceleration value $(42.3 \mathrm{~g})$ was recorded in an attempt where the push occurred on a shoulder and not on a back. Therefore, development of the technically correct defencive player actions on-ice and off-ice allows lowering the head injury risks.

Key words: ice hockey, youth sport, checking, head acceleration, injuries.

Получено 8 февраля 2015 